\title{
Impact Response and Failure Mechanisms of Ultrahigh Modulus Polyethylene Fiber Composites and Polyethylene Fiber-Carbon Fiber Hybrid Composites
}

\author{
X.J. Xian \\ Institute of Mechanics, Chinese Academy of Science, \\ 15 Zhong Guan Cun Road, Beijing, 100080 P.R. China \\ Keywords: Impact Response, Ultrahigh Modulus Polyethylene Fiber, Carbon Fiber, Hybrid \\ Composites, Microscopic Failure Mechanisms
}

\begin{abstract}
The impact response and failure mechanisms of ultrahigh modulus polyethylene (UHMPE) fiber composites and UHMPE fiber-carbon fiber hybrid composites have been investigated. Charpy impact, drop weight impact and high strain rate impact experiments have been performed in order to study the impact resistance, notch sensitivity, strain rate sensitivity and hybrid effects. Results obtained from dynamic and quasi-static measurements have been compared. Because of the ductility of UHMPE fibers, the impact energy absorption of UHMPE fiber composites is very high, thereby leading to excellent damage tolerance. By hybridizing with UHMPE fibers, the impact properties of carbon fiber composites can be greatly improved. The impact and shock failure mechanisms of these composites are discussed.
\end{abstract}

\section{INTRODUCTION}

Impact from foreign objects may produce cracks, delamination and fiber breakage in composite materials, thereby leading to a degradation in strength. Even if there is no visual damage after impact, the compressive strength may be reduced up to $40 \%$ in carbon fiber composites [1]. It is therefore important to find ways to improve the impact resistance and damage tolerance of structural composite materials. Several approaches have been used to improve the impact resistance of carbon fiber composites [2], which include matrix modification, control of interface adhesion, laminate lay-up design, introduction of throughthickness reinforcement (braiding, 3D weaving or stitching), insertion of 'interleaf' layers and hybridization with ductile fibers. The last approach shows good promise because the impact behavior of a composite depends strongly on its reinforcement. By using fibers of high fracture strain or hybridizing such fibers with carbon fibers it is possible to produce composites with high impact resistance.

Since the mid-1970's various reports on the impact improvement of carbon fiber (CF) composites via hybridization with glass or aramid fibers have been presented [3, 4]. In 1980 's an important class of high performance reinforcement - ultrahigh modulus polyethylene fiber (UHMPEF) - has been developed. The advantages of UHMPEF are low 
density ( $\rho \approx 0.97 \mathrm{~g} / \mathrm{cm}^{3}$ ), excellent ductility (with an elongation at break of $3-4 \%$ ), good dielectric properties and superior resistance to impact, wear, moisture and chemical agent $[5,6]$. However, UHMPEF has weaknesses such as poor compressive properties, poor interfacial adhesion, low heat resistance and low creep resistance [6,7], which limit its applications in high performance composite structures. The tensile, compression, flexural, interlaminar shear, and fracture behavior of UHMPE fiber composites and hybrid composites have been investigated [8-16]. However, there are comparatively few works on the impact response and microscopic failure mechanisms at various impact energy levels and at high strain rate. In the present work, the Charpy impact, drop weight impact and high strain rate impact behavior of UHMPE fiber composites and hybrid composites have been studied. The impact response, hybrid effects, notch sensitivity and strain rate effects have been investigated.

\section{CHARPY IMPACT RESPONSE AND FAILURE MECHANISMS OF ULTRAHIGH MODULUS POLYETHYLENE FIBER COMPOSITES AND HYBRID COMPOSITES}

\subsection{Materials and Specimens}

The materials discussed in this Section were Dyneema SK66 UHMPE fiber (UHMPEF) and T300 carbon fiber (CF) reinforced epoxy (EP) composites. SK66 fibers were treated with a chromic acid etching solution followed by thorough rinsing and drying. Five types of unidirectional composites - a UHMPE fiber reinforced composites , a carbon fiber reinforced composites and three types of UHMPEF-CF hybrid composites with different hybrid ratio - were fabricated [13]. The stacking sequences and hybrid ratio are shown in Fig. 1. The fiber volume fraction in the laminates was nominally $55 \%$. A comparison of the basic properties of UHMPE fibers and other advanced fibers are given in Table 1.

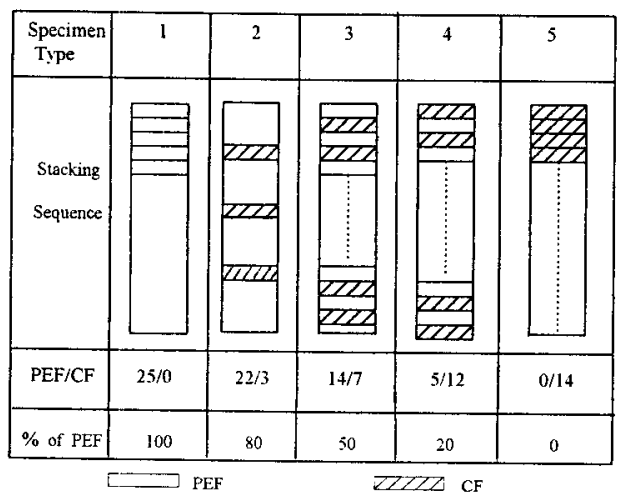

Fig. 1 The stacking sequence and hybrid ratio of UHMPEF-CF/EP[0] specimens 
Table 1 Comparison of Properties of UHMPE Fibers and Other Advanced Fibers

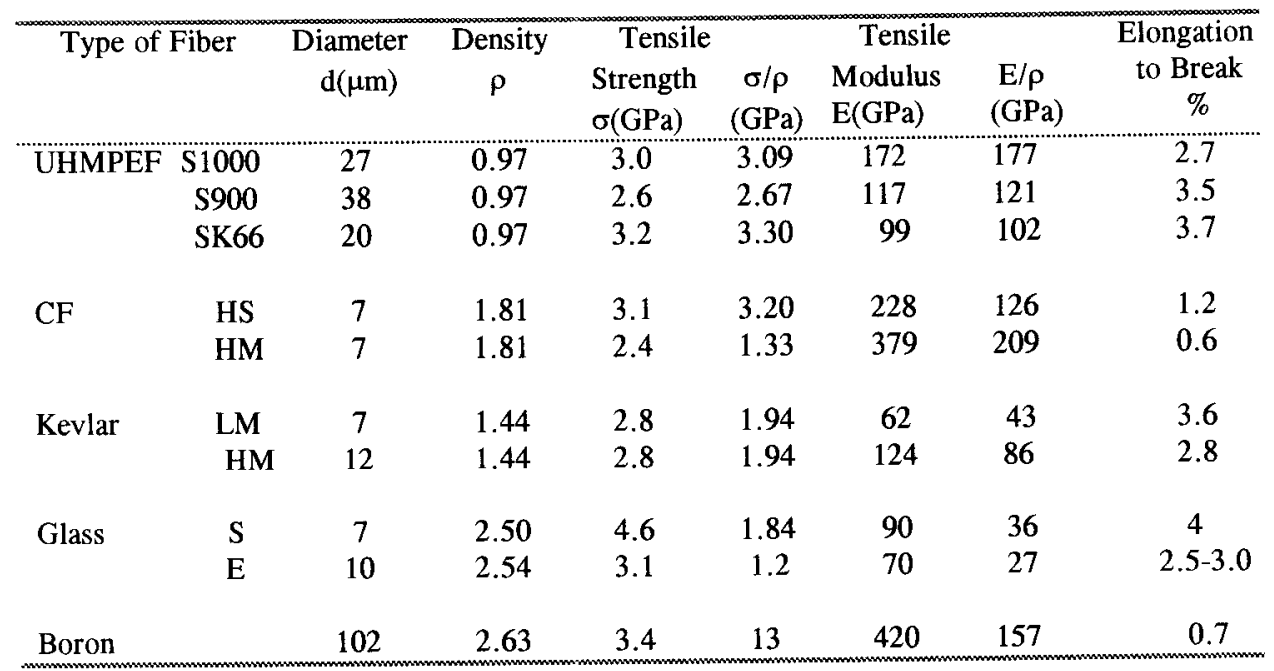

\subsection{Experimental Techniques}

Charpy impact tests were used to evaluate the low energy impact characteristics of the composites. The impact tests were conducted in a CEAST model 6545 Charpy machine. The impact velocity was about $3.46 \mathrm{~m} / \mathrm{s}$. A transducer, attached to the pendulum striker, gave a signal associated with the instantaneous load, which was fed to a transient recorder. A personal computer was used to record and analyze the data, thereby giving the impact load versus time curves.

Notched, unnotched and flat flexure Charpy impact experiments were performed in order to determine the impact history, maximum impact force and total energy absorption of the composites. The loading conditions for the specimens in these three types of Charpy impact tests are shown in Fig. 2. The Charpy impact experiments were conducted according to ASTM standard, and the dimension of specimen was $120 \mathrm{~mm} \mathrm{x}$ $10 \mathrm{~mm} \times 5 \mathrm{~mm}$. For the edge notched specimens, the notch length/specimen width ratio

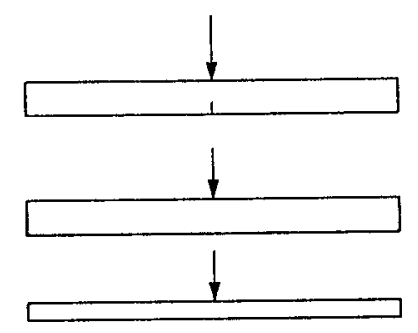

Fig.2 Three different loading conditions for Charpy impact specimen (arrowhead shows loading direction) 
$a / w$ was 0.3 . Static flat flexural tests were also carried out to compare with the dynamic results. The failure mechanisms were investigated using a scanning electron microscope (SEM).

\subsection{Charpy Impact Response and Failure Modes of Notched UHMPE Fiber Composites and Hybrid Composites}

Fig. 3 shows the impact force $\mathrm{F}$ as a function of time $\mathrm{T}$ for the notched UHMPEF/ EP [0] specimen. The curve consisted of two parts. The roughly linear region from the initial point to the point at maximum was associated with damage initiation, so the area under this portion of the curve was called the initiation energy $E_{i .}$. The remaining region , associated with damage propagation and plastic deformation, had a corresponding propagation energy $E_{p}$. The ductility index DI, defined as $D I=E_{p} / E_{i}$ was a measure of the impact toughness of the composites[17]. It was seen from Fig. 3 that the peak impact force for UHMPE/EP[0] was not high and the force dropped slowly to zero after reaching the peak. Consequently, $E_{i}$ was rather low and $E_{p}$ was comparatively high, resulting in a high DI of 6.7. The total energy absorbed $E_{t}\left(=E_{i}+E_{p}\right)$ was also high (see Table 2). In contrast, the $\mathrm{CF} / \mathrm{EP}[0]$ specimen had a high peak force which, however, dropped quickly to zero. Thus both DI and the total energy absorption were low. Fig.4 shows a comparison of the impact response curves for PEF/EP[0], PEF-CF(1:1)/EP[0] and $\mathrm{CF} / \mathrm{EP}[0]$. Through hybridization with UHMPE fibers the impact resistance of the composites was greatly improved because of the increase in $E_{p}$. As shown in Table 2 the impact energies $E_{4}$ for type 2,3 and 4 hybrid composites were, respectively, $88 \%, 132 \%$ and $47 \%$ higher than that of the carbon fiber composites. The ductility indices were higher by more than a factor of 4 . Type 3 composite had the highest $E_{t}$ and DI because it had the largest number of UHMPEF-CF interfaces[14].

Table 2 Notched Charpy Impact Energy Absorption of UHMPEF-CF/EP[0] Specimen

\begin{tabular}{|c|c|c|c|c|c|}
\hline Type of specimen & 1.PEF/EP[0] & $\begin{array}{l}\text { 2. PEF-CF } \\
(4: 1) / E P[0]\end{array}$ & $\begin{array}{l}\text { 3.PEF-CF } \\
(1: 1) / E P[0]\end{array}$ & $\begin{array}{l}\text { 4.PEF-CF } \\
(1: 4) / E P[0]\end{array}$ & 5.CF/EP[0] \\
\hline $\begin{array}{l}\text { Total Energy } \\
\text { Absorption } E_{t}(J)\end{array}$ & 12.3 & 11.8 & 13.9 & 8.8 & 6 \\
\hline $\begin{array}{c}\text { Ductility Index } \\
\text { DI }\end{array}$ & 6.7 & 7.7 & 8.1 & 4.2 & 11 \\
\hline
\end{tabular}

Fig. 5 shows the impact failure modes of notched specimens of the five type of composites. Only the CF/EP[0] specimen was fractured into two pieces. The other four specimens were not completely broken as a result of the high ductility of UHMPE fibers. For the UHMPEF/EP[0] specimen, the fibers exhibited large deformation but are not broken, and the major damage modes are interface debonding and delamination (Fig.6). The splitting between the multiplex layers was the feature of dynamic failure mode, which did not occur in specimens subjected to the static notched fracture test [12]. Hybrid specimens showed almost no UHMPE fiber breakage, while carbon fiber breakage was evident. Both kinds of fibers preserved their original features.Various failure patterns were exhibited for different hybrid ratio composites. In Type2 UHMPEF-CF(4:1) /EP[0] specimens (Fig.7), the main failure mechanism was plastic deformation of the dominant UHMPE fiber and 


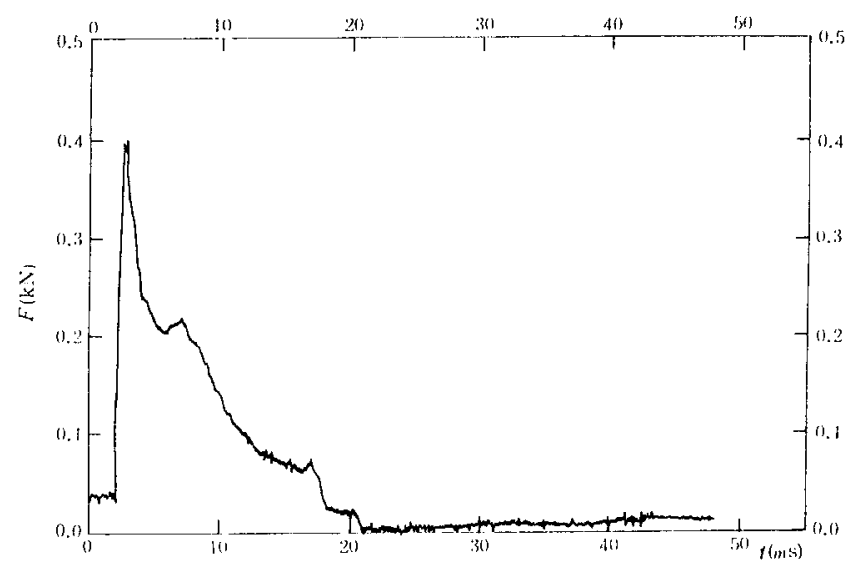

Fig.3 F - T Relationship for PEF/EP[0] notched specimen upon Charpy impact

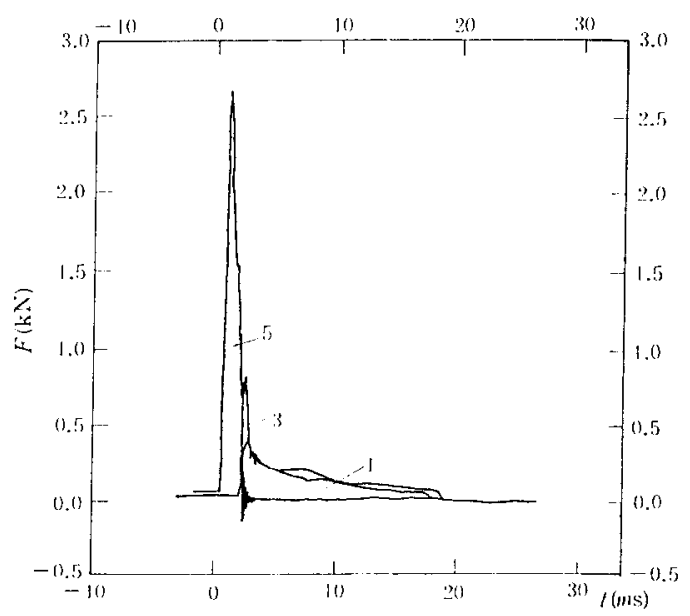

Fig. 4 F-T relationship for PEF/EP[0](curve 1), PEF-CF(1:1)/EP[0](curve 3) and $\mathrm{CF} / \mathrm{EP}[0]$ (curve5) notched specimens upon Charpy impact

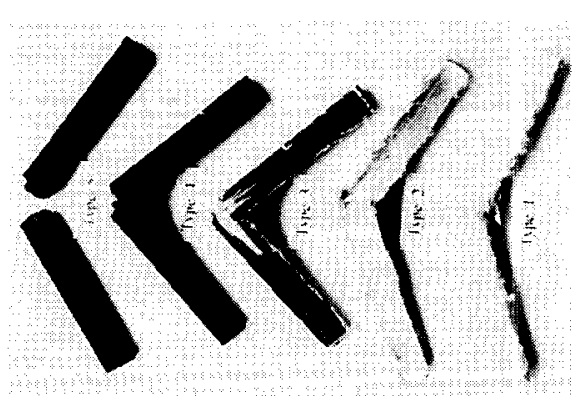

Fig.5 Failure modes of five Types of notched specimens after Charpy impact

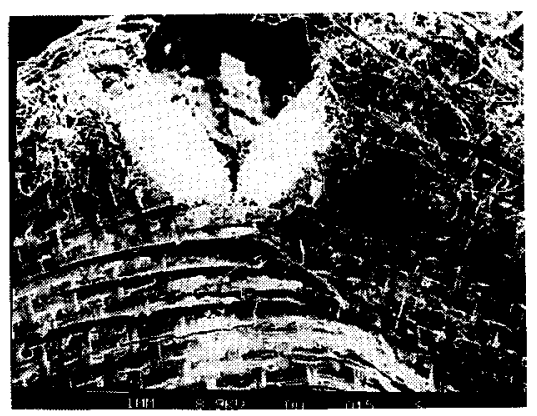

Fig.6 SEM micrograph showing cracks propagation and multiplex split in $\mathrm{PEF} / \mathrm{EP}$ [0]notched specimen after Charpy impact 
delamination, accompanied by breakage of a few carbon fiber. Type 4 UHMPEF$\mathrm{CF}(1: 4) / \mathrm{EP}[0]$ specimen (Fig. 8a) contained much less PE fibers and as a result more carbon fibers were broken and few PE fibers deformed. Carbon fibers extruded from the PE fiber layers (Fig. 8b) and led to large deformation (Fig.4). Fig.9 is an SEM micrograph of a Type 3 specimen taken from the notch front. The two kinds of fibers were present in equal proportions and both carbon fiber breakage as well as UHMPE fiber deformation could be seen clearly. Type 3 composites had the highest impact energy value due to the multiplex delaminations occurring at most of the UHMPEF-CF interfaces.

\subsection{Charpy Impact Response of Unnotched UHMPE Fiber Composites and Hybrid Composites}

In order to evaluate the notch sensitivity of UHMPE fiber composites and hybrid composites, unnotched specimens were subjected to Charpy impact tests using similar methods as described above (Fig. 2b). Fig. 10 shows the Load (F) vs Time (T) curve of UHMPEF/EP[0] unnotched specimen. Table 3 shows the impact energy absorption of unnotched hybrid composites. It is evident that impact resistance was improved by hybridization. Again, Type 3 composites had the largest $E_{q}$ values, for reasons discussed previously. When the F-T curves of notched and unnotched specimens were compared, the initiation to lead peak stages were found to be similar. However, subsequent damage propagation stages were different in terms of energy absorption. In unnotched specimens, when load (F) dropped to $50 \%$ of $\mathrm{F}_{\text {max }}$ deformation increased rapidly, resulting in a platform in the F-T curve. This is followed by a rapid decline to zero. Such behaviour demonstrates that deformation is the major mechanism of energy absorption in unnotched specimens. When values obtained for notched and unnotched specimens were compared (Tables 2 and 3), it is apparent that for Type 1, 2 and 3 composites, notched specimens absorbed more energy $E_{t}$ than the corresponding unnotched specimens. However, for Type 4 and Type 5 composites, $\mathrm{E}_{\mathrm{t}}$ was much lower in notched specimens. Such results indicate that notch sensitivity varies according to hybrid ratio. Types 1,2 and 3 composites contained over $50 \%$ of the ductile PE in its total fiber content, so that more significant plastic deformation occured near the notch tip, leading to blunting of the tip as well as multiple-layer splitting. The overall effect is that greater energy is absorbed in notched specimens, resulting in reduce notch sensitivity. By contrast, Type 4 and Type 5 composites consisted of over $50 \%$ of the brittle carbon fiber in its total fiber content. This facilitated greater stress concentration at the notch tip, and resulted in easier crack initiation, propagation as well as carbon fiber breakage. Thus these two types of composites have a greater notch sensitivity.

Table 3 Unotched Charpy Impact Properties of UHPEF-CF/EP[0] Composites

\begin{tabular}{|c|c|c|c|c|c|}
\hline Type of Specimen & $\begin{array}{c}\text { 1.PEF/EP } \\
{[0]}\end{array}$ & $\begin{array}{l}\text { 2.PEF-CF(4:1) } \\
\text { /EP[0] }\end{array}$ & $\begin{array}{l}\text { 3.PEF-CF(1:1) } \\
\text { /EP[0] }\end{array}$ & $\begin{array}{l}\text { 4.PEF-CF(1:4) } \\
\text { /EP[0] }\end{array}$ & $\begin{array}{c}\text { 5. CF/EP } \\
{[0]}\end{array}$ \\
\hline Total Energy & & & & & \\
\hline Absorption) $\mathrm{E}_{\mathrm{t}}(\mathrm{J})$ & 9.7 & 11.2 & 12.5 & 11.5 & 8.3 \\
\hline
\end{tabular}




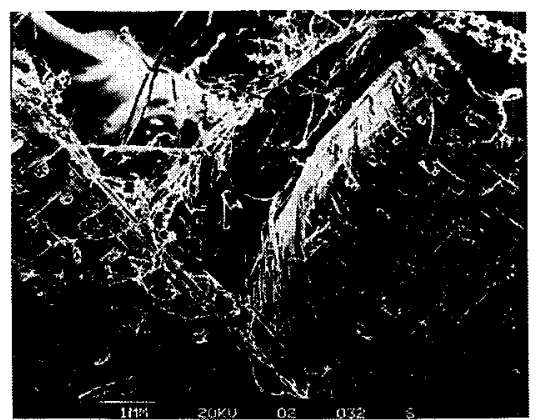

Fig. 7 Fractograph at notch tip showing the deformation and delamination of PEF-CF (4:1)/EP [0] notched specimen upon Charpy impact

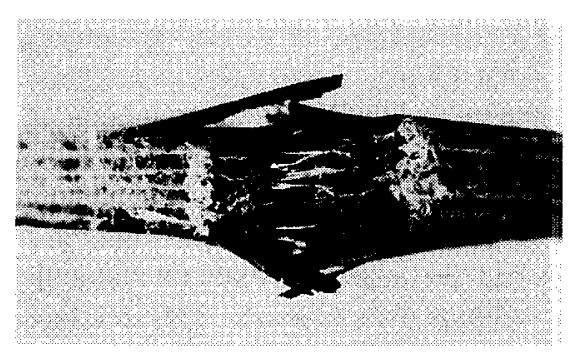

Fig. 8b Failure mode of PEF-CF $(1: 4) / E P[0]$ notched specimen upon Charpy impact

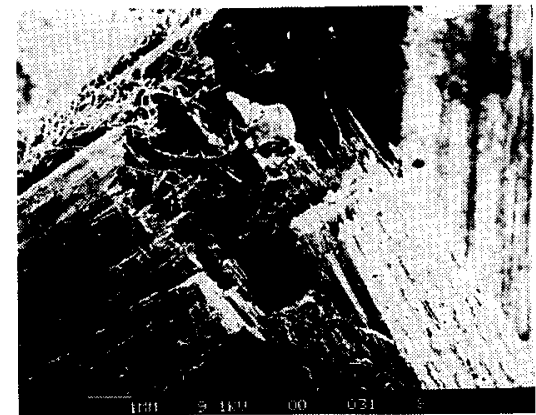

Fig. 8a SEM micrograph showing broken $\mathrm{CF}$ and deformed PEF in the notched tip region of PEF-CF(1:4)/EP [0] notched specimen upon Charpy impact

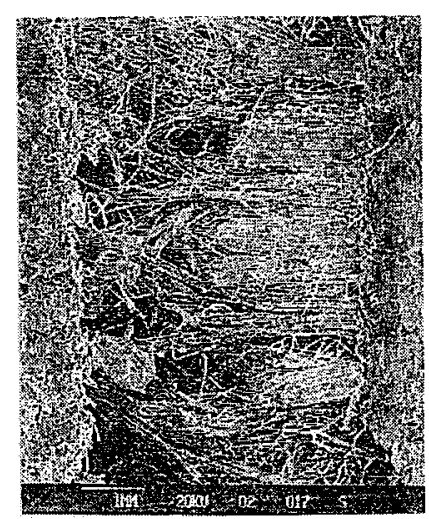

Fig. 9 SEM micrograph showing broken $\mathrm{CF}$ and deformed PEF in PEF-CF(1:1)/ EP[0]notched specimen upon Charpy impact

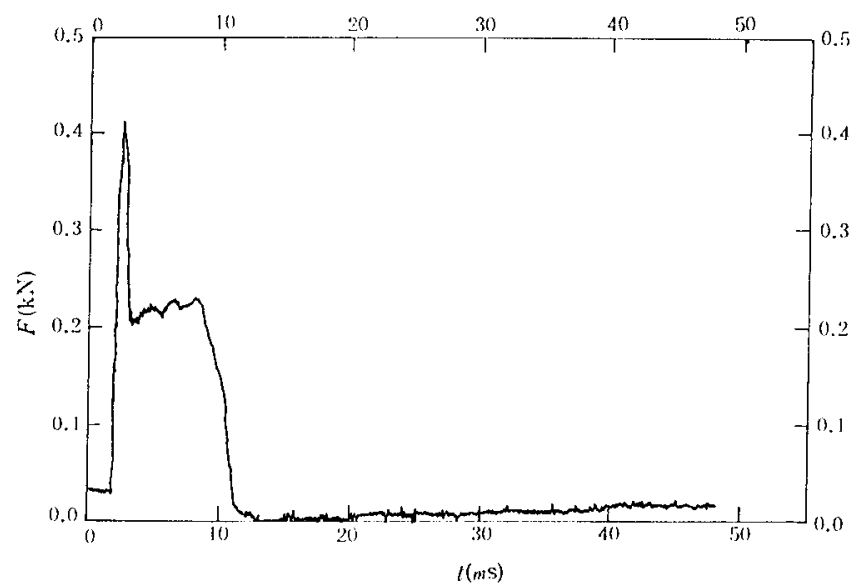

Fig.10 F-T relationship for PEF/EP[0] unnotched specimen upon Charpy impact 


\subsection{Flat Charpy Impact Behaviour and Failure Mechanism of UHMPE Fiber Composites and Hybrid Composites}

Flat Charpy impact (Fig. 2c) is one type of dynamic three-point bending method, and can be used to compare quasi-static flexure properties of materials. Fig. 11-13 show the Flat Charpy impact histories of Type 1,3 and 5 composites respectively. In the F-T curve of a UHMPEF/EP[0] specimen, a low load peak was observed, which showed a slow decline with increasing impact propagation energy and total energy absorption. In contrast, the CF/EP[0] specimen showed a high load peak in the F-T curve, which dropped rapidly to zero. $E_{p}$ and DI values were lowest, and the specimen broke into two pieces after impact (Fig. 14). Maximum impact force in hybrid composites were greater than in UHMPEF composites, and impact propagation as well as total energy were greater than CF composites. In the hybrid composites, impact force caused synchronous deformation of the UHMPE fibers while carbon fibers were unable to deform synchronously with the pendulum impact, and fracture occurred. Such breakage of carbon fibers also limited the deformation of the UHMPE fibers, which tended to fold over. As a result hybrid composites did not break up into two separate pieces following flat Charpy impact (Fig. 14). This condition is true even for Type 4 composites, where UHMPE fibers make up only $20 \%$ of the total fiber content(Fig. 15).

In UMPEF/EP[0] composites, flexural plastic deformation is the major failure mode (Fig. 16), while delamination was the predominant failure mechanism of hybrid composites (Fig. 14). Table 4 shows the experimental results of flat Charpy impact and quasi-static flexure. These results show that Charpy impact properties and static flexural strength of carbon fiber composites have been significantly improved by hybridizing with UHMPE fibers. Type 3 composites had the highest total energy and lowest deformation. Delamination often occurred between adjacent layers of different fibers rather than within a homogeneous fiber layer. Because Type 3 composites had the largest number of changing fiber layers (Fig.1), it absorbed more energy during impact delamination and interface debonding (Fig. 17). The failure modes (Figs.15 and 18) and F-T curves of dynamic and quasi-static flexure were similar in appearance. Overall, the damage was more severe upon impact. Hybridization caused improvements which presented in impact resistance for $\mathrm{CF}$ composites and flexural properties for PEF composites (Table 4)

Table 4 Flat Charpy Impact Properties of UHMPE-CF/EP[0] Composites

\begin{tabular}{lccccc} 
Type of Specimen & $\begin{array}{c}1 . P E F / E P \\
{[0]}\end{array}$ & $\begin{array}{c}2 . P E F-C F \\
(4: 1) / E P[0]\end{array}$ & $\begin{array}{c}3 . P E F-C F \\
(1: 1) / E P[0]\end{array}$ & $\begin{array}{c}4 . P E F-C F \\
(1: 4) / E P[0]\end{array}$ & $5 . C F / E P[0]$ \\
\hline Total Energy Absorption $E_{t}(\mathrm{~J})$ & 10.1 & 9.6 & 10.7 & 9.9 & 6.9 \\
Ductility Index DI & 8.7 & 6.6 & 6.8 & 6.0 & 1.8 \\
Flexural Stress $\sigma_{b}(\mathrm{MPa})$ & 169 & 178 & 238 & 244 & 691
\end{tabular}




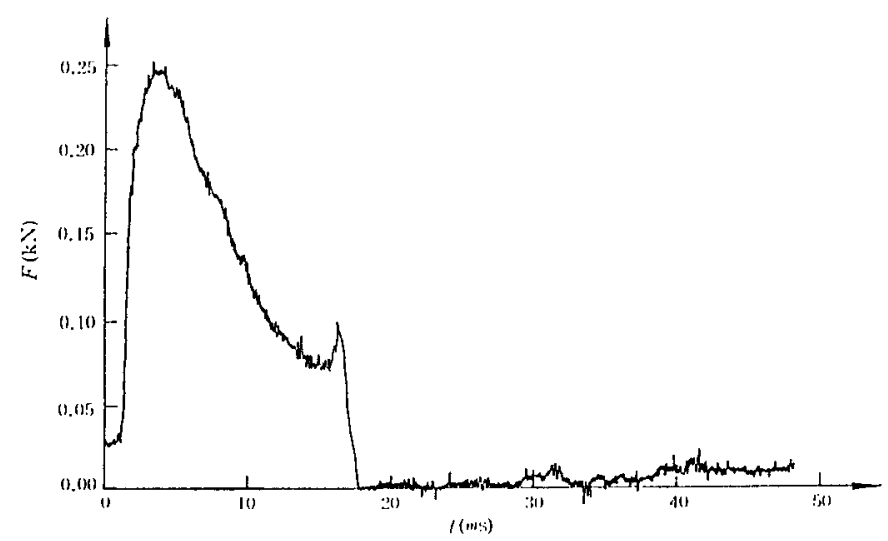

Fig. 11 Relationship between F - T for PEF/EP[0] specimen upon flat Charpy impact

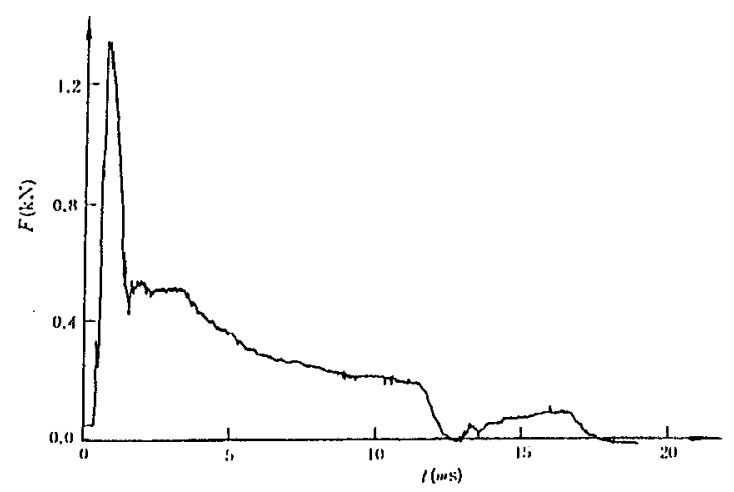

Fig. 12 F - T relationship for PEF-CF(1:1)/EP[0] specimen upon flat Charpy impact

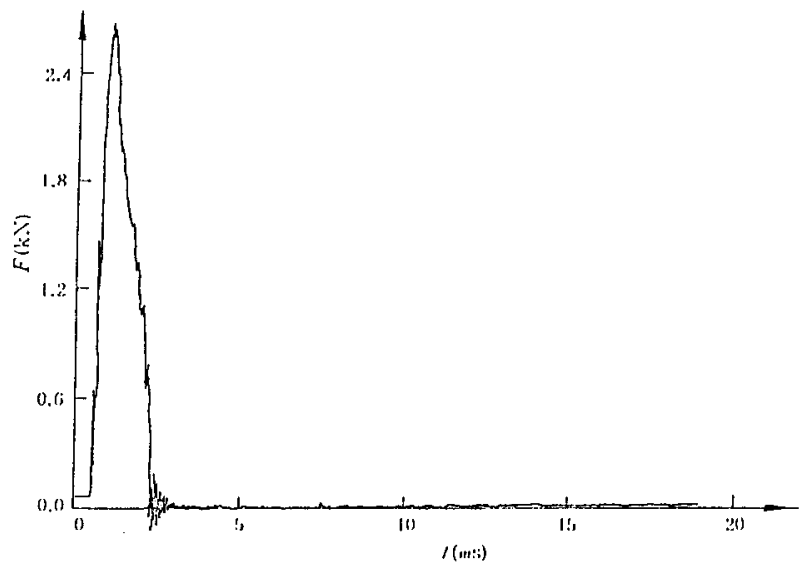

Fig.13 F - T relationship for CF/EP[0] specimen upon flat Charpy impact 


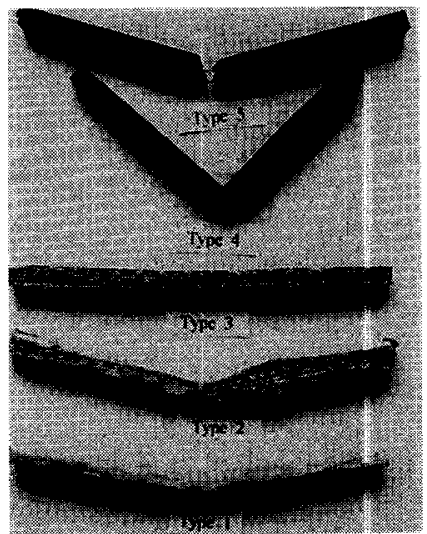

Fig. 14 Failure modes of five types specimens after flat Charpy impact

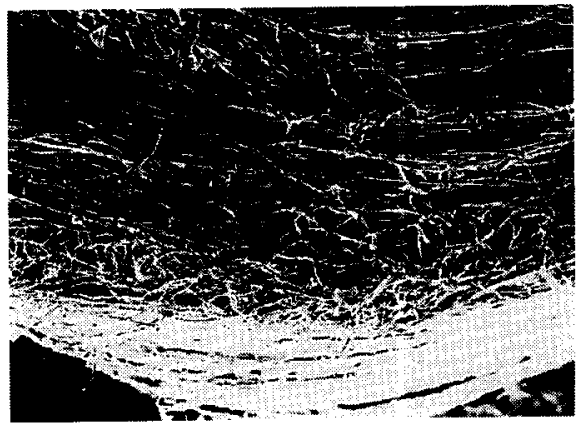

Fig.16 Flexural plastic deformation of PEF/EP[0] specimen after flat Charpy impact

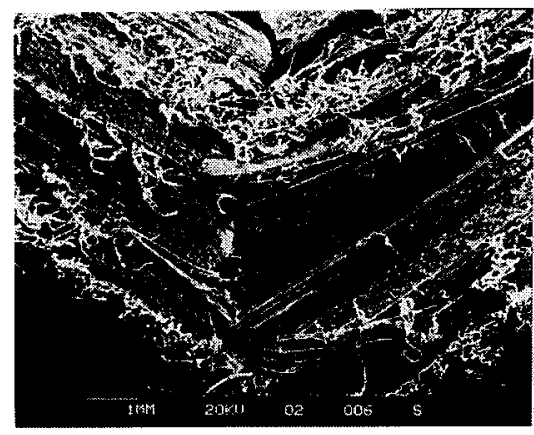

Fig.15 Flexural failure mode of PEF-CF(1:4) /EP[0] specimen after flat Charpy impact

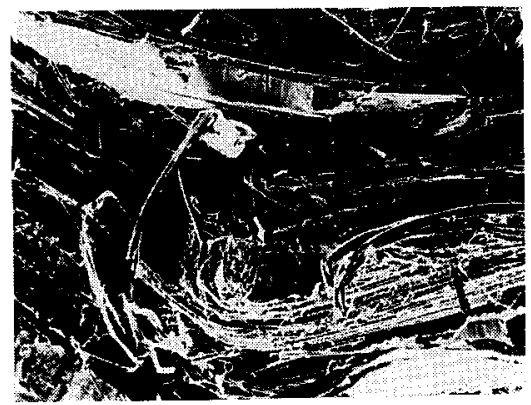

Fig. 17 Fractograph showing breakage of $\mathrm{CF}$ with deformation of PEF in PEF-CF(1:1)/ $\mathrm{EP}[0]$ specimen after flat Charpy impact

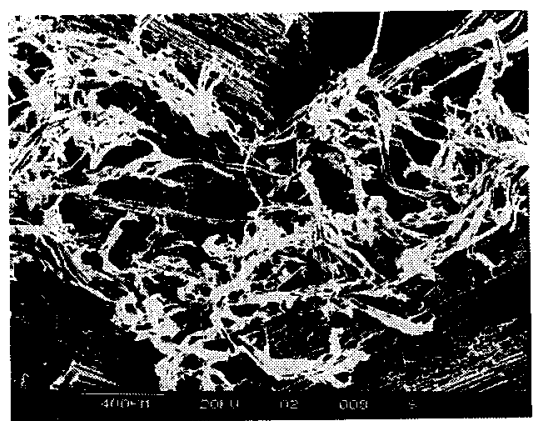

Fig.18 Static flexural failure mode of PEF-CF(1:4)/EP[0] specimen 


\section{DROP WEIGHT IMPACT RESISTANCE AND FAILURE MODES OF ULTRAHIGH MODULUS POLYETHYLENE FIBER COMPOSITES}

\subsection{Materials, specimens and Experimental Techniques}

Drop weight impact is an impact test method which most closely simulates actual low velocity impact situations. Apart from the advantage of allowing evaluation of entire damage pattern, it can also provide larger incident impact energy than Charpy impact. Thus, this method is suitable for highly ductile materials or thick specimens.

The reinforcement used in this work was UHMPE Spectra 1000 (S1000) fiber which had been treated by corona. Woven fabrics of $\mathrm{S} 1000$ fiber were embedded in matrices of either low density polyethylene (LDPE) or epoxy (EP) of low heat durability. Since these composites could not be shaped easily by conventional machining methods without harmful effects, specimens used in this work were machined by high speed water jet supplied through a Markz Model IIX intensifier pump. During the machining process, the samples were eroded by a high speed, high pressure ( $6000 \mathrm{psi})$ water jet containing emery powder, to an accuracy of within $0.1 \mathrm{~mm}$. S1000 reinforced LDPE specimens (S1000/LDPE[W]) measured $100 \mathrm{~mm} \times 100 \mathrm{~mm} \times 2.8 \mathrm{~mm}$, while S1000/EP [W] specimens measured $110 \mathrm{~mm} \times 100 \mathrm{~mm} \times 6.7 \mathrm{~mm}$.

Impact experiments were conducted in a Rheometrics RDT-5000 drop weight tester. The specimen was supported by a ring to eliminate edge wrinkling. The diameter of the hemispherical head of the dart was $20 \mathrm{~mm}$, and the weight of the dart was fixed at $3.17 \mathrm{~kg}$. Impact energy was changed by varying the impact velocity of the dart, and the force was recorded as a function of time. Three impact incident velocities (V) were used to obtain various impact energy levels for experiments. The aim was to evaluate the impact responses in three states: initial damage, large deformation and penetration. The effects of various incident energy and matrices on the impact properties and failure modes were thus investigated.

\subsection{Drop Weight Impact Response of S1000 Woven Fabric Reinforced LDPE Matrix Composites (S1000/LDPE[W])}

At a low impact velocity of $5.09 \mathrm{~m} / \mathrm{s}, \mathrm{S} 1000 / \mathrm{LDPE}[\mathrm{W}]-1$ specimen showed a large deformation (d) which was associated with a depression of $12 \mathrm{~mm}$. The bottom face (exit side) showed tensile deformation of UHMPE fibers although no damage failure was observed. The total energy absorption $E_{t}$ was $41 \mathrm{~J}$. A summary of the drop weight impact test results are presented in Table 5. When incident velocity $(V)$ was increased to $10.3 \mathrm{~m} / \mathrm{s}, E_{t}$ of S1000/LDPE[W]-4 was 169J. A typical impact response curve of load (F) vs time (T) for non-penetrated specimen is shown in Fig. 19. Prior to the load peak, the F-T relationship was quite linear, and the curve approach the load peak smoothly, demonstrating excellent ductility of the material. Fig. 20 shows the large plastic deformation within the support ring, with an extruded wrinkle on the entrance side where contact is made with the impactor. The depression diameter was $20 \mathrm{~mm}$ and depth was $17 \mathrm{~mm}$, with the bottom of the specimen becoming thinner. A few matrix cracks were visible on the tensile face but penetration was not effected. Wrinkling and delamination could be observed in the middle part of the edge around the depression. These features are typical of impact failure in composite materials capable of withstanding high tensile stress and high strain rates. When $\mathrm{V}$ was increased to 
Table 5 Drop Weight Impact Properties of $\mathbf{S 1 0 0 0}$ woven fabric composites

\begin{tabular}{|c|c|c|c|c|c|c|}
\hline Specimen & \multicolumn{2}{|c|}{ S1000/LDPE[W] } & \multicolumn{4}{|c|}{$\mathrm{S} 1000 / \mathrm{EP}[\mathrm{W}]$} \\
\hline $\operatorname{Dimension}(\mathrm{mm})$ & $100 \times 10$ & $0 \times 2.8$ & & $110 \times 1$ & $00 \times 6.7$ & \\
\hline Incident Velocity $\mathrm{V}(\mathrm{m} / \mathrm{s})$ & 5.09 & 10.3 & 14 & 5.02 & 11.5 & 17.5 \\
\hline $\begin{array}{l}\text { Maximum Impact Force } \\
\mathrm{F}_{\max }(\mathrm{kN})\end{array}$ & 0.44 & 17.5 & 21.7 & 1.61 & 19.7 & 42.2 \\
\hline $\begin{array}{l}\text { Maximum Impact Energy } \\
\mathrm{E}_{\max }(\mathrm{J})\end{array}$ & 7.41 & 153 & 72.2 & 14.8 & 130 & 1206 \\
\hline $\begin{array}{l}\text { Total Energy Absorption } \\
E_{t}(J)\end{array}$ & 20.2 & 169 & 295 & 20.4 & 199 & 486 \\
\hline $\begin{array}{l}\text { Energy per unit Length } \\
\mathrm{S}(\mathrm{kJ} / \mathrm{m})\end{array}$ & & & 1639 & & & 1157 \\
\hline Failure Modes & Delamination & Damage & Penetration & Delamination & Damage & Penetration \\
\hline
\end{tabular}

$14 \mathrm{~m} / \mathrm{s}$, S1000/LDPE[W]-7 specimen was penetrated although a few fiber bundles were not completely broken (Fig. 21). The rupture diameter was $20 \mathrm{~mm}$, and $\$ 1000$ fibers were broken during flexural impact. Internal delamination was evident in the transitional position between the hole and the support ring. A typical penetrating impact response curve of S1000/LDPE[W]-7 is shown in Fig. 22. The failure process was quite complex. As some fibers and layers fractured, the impact force decreased and stress was redistributed. This caused other layers to sustain further loads, and a smaller load peak was observed after the occurrence of the first peak. After penetration, the impact load dropped to very low levels due to the friction between the dart and the hole. A total energy $E_{t}$ of $295 \mathrm{~J}$ and energy per unit length (=thickness) $\mathrm{S}$ of $105 \mathrm{~J} / \mathrm{m}$ were recorded. The impact resistance of S1000/LDPE[W] was found to be excellent.

\subsection{Drop Weight Impact Resistance and Failure Modes of S1000 Fiber Woven Fabric Reinforced Epoxy Matrix Composites (S1000/EP[W])}

In general, F-T relationships in S1000/EP[W] composites subjected to lower and medium impact velocities were similar to those found in S1000/LDPE[W] composites. At V=5.02m/s, $E_{t}$ was $20.4 J$ and $d_{\max }$ at impact point was $14.8 \mathrm{~mm}$. Note that specimen thickness was $6.7 \mathrm{~mm}$. At higher input energy $(\mathrm{V}=11.5 \mathrm{~m} / \mathrm{s})$, a large deformation was recorded and at $\mathrm{V}=15.5 \mathrm{~m} / \mathrm{s}$, a circular depression of $15 \mathrm{~mm}$ depth at the impact side resulted, with some fiber extrusion and shear failure being visible in the material around the internal edge of the supporting ring. Cracks were distributed, and some of the woven fabric checks spread out. Stress concentration on the tensile side resulted in some fiber breakage, but penetration had not been effected(Fig. 23). Penetration only occurred when the impact velocity had reached 
$17.5 \mathrm{~m} / \mathrm{s}$ (Fig. 24), and fibers tore away and split on the exit side. Failure modes were slightly brittle rupture of the epoxy matrix and fiber pull-out. $E_{t}$ was $486 \mathrm{~J}$ and energy per unit length was $72.5 \mathrm{~J} / \mathrm{m}$.

The data showed that impact resistance of S1000/LDPE[W] composites was $45 \%$ higher than those of S1000/EP[W] composites. This was because the ductility of the LDPE matrix was far superior to that of epoxy, and also because better fiber-matrix adhesion occurred in S1000/LDPE[W] composites due to a greater chemical similarity between the LDPE matrix and UHMPE fibers.

Comparing this set of data with other studies on drop weight impact resistance of carbon fiber composites [18], we find that impact properties of UHMPE fiber composites were superior.

Table 6 compares drop weight impact properties of UHMPE Spectra fiber composites against other advanced composites [19] subjected to similar impact velocities. Total energy absorption $\mathrm{E}_{\mathrm{t}}$ of Spectra fiber composites was $6.8,8$ and 21.5 times that of S-2 glass fiber composites, Kevlar fiber composites and high modulus carbon fiber composites respectively. After drop weight impact, UHMPE fiber specimens were depressed hemispherical within the support ring, and some micro-damage occurred at the bottom although penetration did not occur. In contrast, the other three kinds of composites discussed above were penetrated in various failure modes. Thus, it may be concluded that the impact resistance and damage tolerance of UHMPE fiber composites are excellent.

Table 6 Comparison of Drop Weight Impact Properties on UHMPE Spectra Fiber Composites and Other Advanced Fiber Composites

\begin{tabular}{|c|c|c|c|c|c|c|c|c|}
\hline \multirow[t]{2}{*}{ Materials } & \multirow[t]{2}{*}{ Layers } & \multicolumn{2}{|c|}{$\begin{array}{l}\text { Ultimate Impact } \\
\text { Force } F_{u l t}\end{array}$} & \multicolumn{2}{|c|}{$\begin{array}{c}\text { Energy Corresponding } \\
E_{\text {ult }}(J)\end{array}$} & \multicolumn{2}{|c|}{$\begin{array}{l}\text { Total Energy } \\
\text { Absorption }\end{array}$} & \multirow[t]{2}{*}{$\begin{array}{l}\text { Failure } \\
\text { Mode }\end{array}$} \\
\hline & & $\mathrm{F}_{\mathrm{ult}}(\mathrm{N})$ & Index* & $E_{\mathrm{ult}}(J)$ & Index & $\mathrm{E}_{\mathrm{ult}}(\mathrm{J})$ & Index & \\
\hline Spectra Comp. & 5 & 7356 & 100 & 99.3 & 100 & 114 & 100 & $\begin{array}{l}\text { non- } \\
\text { penetrated }\end{array}$ \\
\hline S-2 GF Comp. & 5 & 1645 & 22 & 3.86 & 4 & 16.8 & 15 & penetrated \\
\hline KF Composites & 5 & 1129 & 15 & 2.73 & 3 & 14 & 12 & penetrated \\
\hline CF Composites & 5 & 592 & 8 & 2.68 & 3 & 5.3 & 5 & penetrated \\
\hline
\end{tabular}

*Index 100 represent the impact properties of Spectra fiber composites, others less 100.

GF - Glass fiber, KF - Kevlar fiber, CF - Carbon fiber 


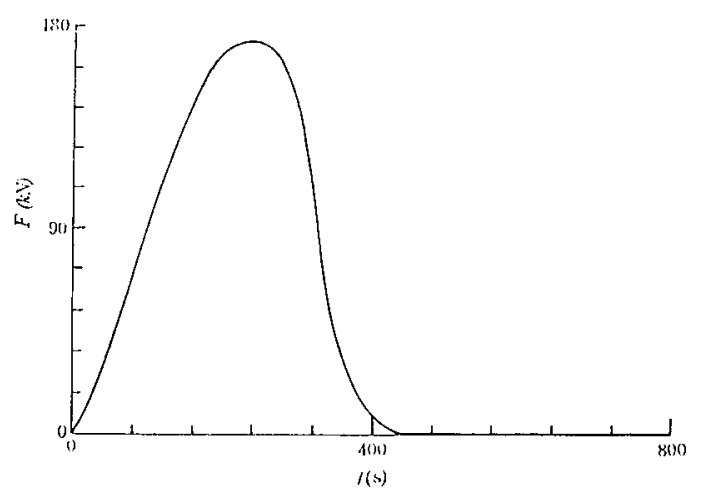

Fig. 19 F-T relationship for S1000/LDPE[W] specimen upon drop weight impact $(\mathrm{V}=10.3$ $\mathrm{m} / \mathrm{s}$ )

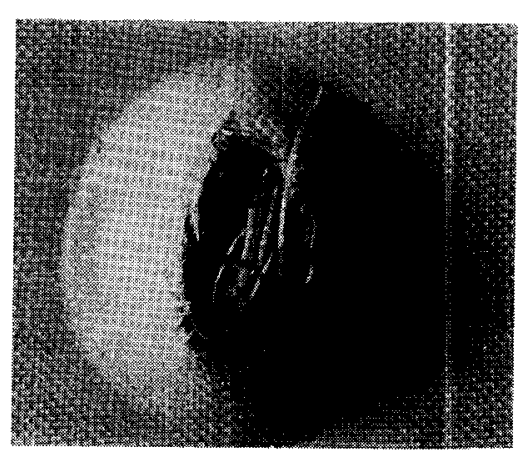

Fig.21 Penetrated failure of $\$ 1000$ /LDPE[W] specimen by drop weight impact $(V=14 \mathrm{~m} / \mathrm{s})$

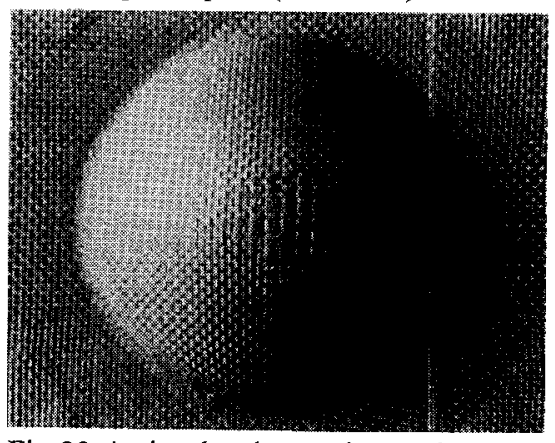

Fig. 23 A circular depression and some woven fabric checks spread of S1000/EP[W] specimen by drop impact $(\mathrm{V}=15.5 \mathrm{~m} / \mathrm{s})$

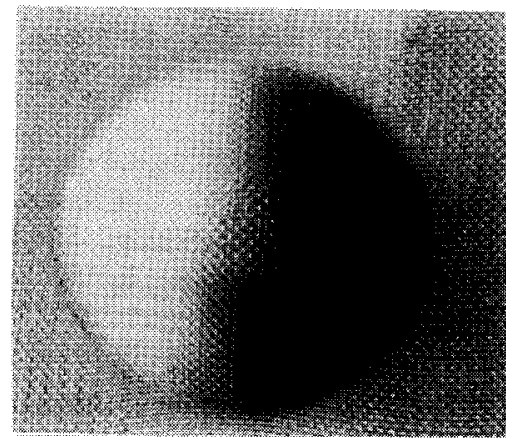

Fig.20 A large plastic deformation and wrinkle of S1000/LDPE[W] specimen by drop weight impact $(\mathrm{V}=10.3 \mathrm{~m} / \mathrm{s})$

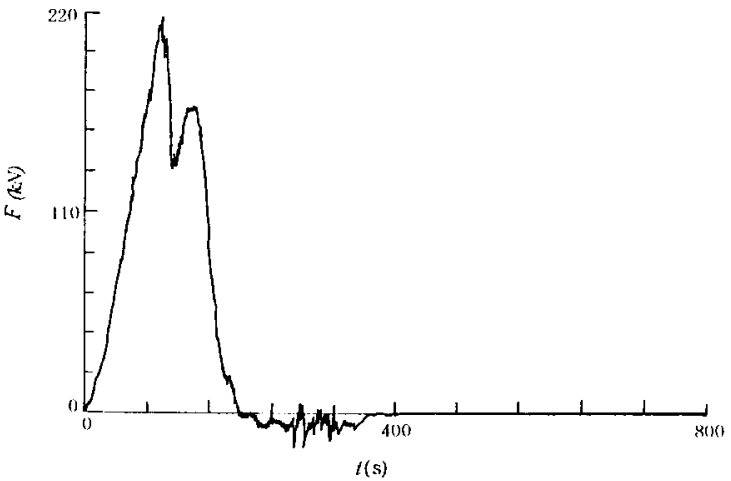

Fig. 22 F-T relationship for S1000/LDPE[W] specimen upon drop weight impact( $\mathrm{V}=14 \mathrm{~m} / \mathrm{s})$

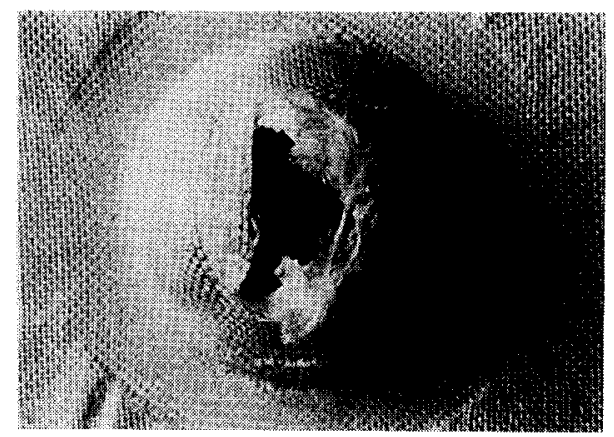

Fig. 24 Penetrated rupture of S1000/ EP[W] specimen by drop weight impact $(\mathrm{V}=17.5 \mathrm{~m} / \mathrm{s})$ 


\section{HIGH STRAIN RATE COMPRESSION IMPACT BEHAVIOUR OF ULTRAHIGH MODULUS POLYETHYLENE WOVEN FABRIC COMPOSITES}

\subsection{Experimental Materials and Methods}

UHMPE woven fabric composites are materials suitable for application in the manufacture of bullet-proof clothing and light-weight armors, due to their superior energy absorption ability. In these applications, the material is subjected to vary rapid loading, where the strain rate can attain high values of $10^{3}-10^{5} \mathrm{~s}^{-1}$. In general, impact resistance and failure modes vary with strain rates. In order to understand the influence of high strain rate on UHMPE fiber composites, a projectile impact experimental study has been performed using a Split Hopkinson Pressure Bar system (SHPB). The dynamic histories and constitutive relations were studied. Earlier studies using the Hopkinson bar were conducted on metals, by applying low velocity and limited increases in strain rates[20]. Since 1980's, high strain responses and shock dynamic mechanics of advanced composite materials were studied, and nowadays, it is common to apply strain rates of $10^{2}-10^{4} \mathrm{~s}^{-1}$, by SHPB, which are within a suitable range for studying composite materials. Information comparing glass and carbon fiber composites using this technique is available [21], but information on the high strain rate behaviour in polyethylene fiber composites is scarce [22]. In this study, a strain rate of $10^{3} \mathrm{~s}^{-1}$ was applied in dynamic tests. Shock damage in composite materials are generally considered in relation to compression strength under shock loading. In general, strain rate sensitivity of polymers and composites are much higher than that of metals. Characteristics of the fiber, matrix and composites are also more complex than metals. In order to reduce the effects of boundary separation, cross sectional areas (A) of composite material specimens are generally bigger than those of the bars in compressive tests, while for metal specimens, A is smaller than the bars. Composites specimens for this dynamic compression tests were $15 \mathrm{~mm} \times 15 \mathrm{~mm}$ $x 6.6 \mathrm{~mm}$. Specimens were made from woven fabrics of $\mathrm{S} 1000$ fiber $\left(\mathrm{V}_{\mathrm{f}} 75 \%\right)$ reinforced an epoxy matrix (S1000/EP[W]).. The experimental setup is shown in Fig. 25. The SHPB apparatus consisted of a stress pulse generator system, input and output bars, and the measuring system. A stress wave was generated by means of an air projectile impact,

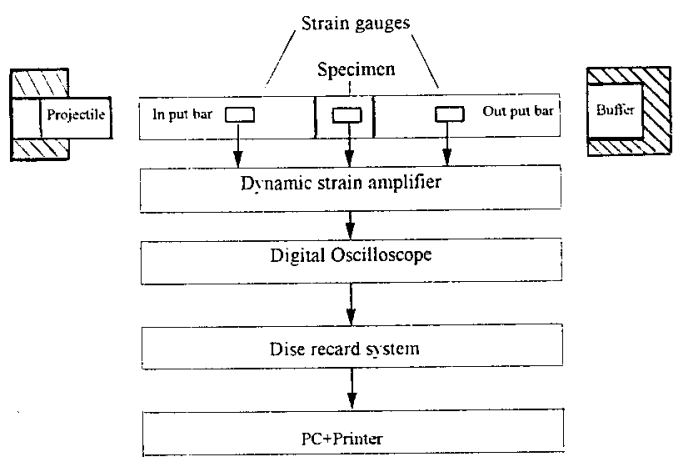

Fig. 25 Diagram of a Split Hophinson Pressure Bar apparatus system 
and the propagation of this wave was analyzed assuming the one-dimensional theory, and measuring with strain gauges the elastic deformations produced in different points of the bars system. Projectile velocity was measured by means of a speed chronometer ( $1 \mathrm{mw} \mathrm{He}-\mathrm{Ne}$ Laser, X2).

\subsection{High Strain Rate Transverse Compression Impact Responses of UHMPE Woven Fabric/Epoxy Composites (S1000/EP[W])}

In order to evaluate the influence of strain rate on samples, quasi-static transverse compressive tests were conducted first. The loading direction was vertical to the surface of the specimen. Strain rate was $10^{-3} \mathrm{~s}^{-1}$ and the static compressive strength $\sigma_{\mathrm{c}}$ was $106 \mathrm{MPa}$

Five projectile velocities, i.e. five strain rates, were applied to the specimens in SHPB. The stress $\sigma$, strain $\varepsilon$ and strain rate $\dot{\varepsilon}$ in the specimen were determined based on the hypothesis of equilibrium and assuming uniform strain along the specimen. Mean strain $\varepsilon$ of the specimen was obtained from strain measurements on the input and output bars for the incident wave, reflective wave and transmissive wave, $\varepsilon_{\mathrm{I}}(\mathrm{t}), \varepsilon_{\mathrm{r}}(\mathrm{t}), \varepsilon_{\mathrm{t}}(\mathrm{t})$, and then by applying the following equation[23]:

$$
\varepsilon=C / L_{s} \int_{i}\left[\varepsilon_{i}(t)-\varepsilon_{\mathrm{r}}(t)-\varepsilon_{\mathrm{t}}(\mathrm{t})\right]
$$

The mean stress is:

$$
\sigma=1 / 2\left[\mathrm{~A}_{0} / \mathrm{A}_{\mathrm{s}}\left(\sigma_{\mathrm{s} 1}+\sigma_{\mathrm{s} 2}\right)\right]=\mathrm{E} / 2\left\{\mathrm{~A}_{\mathrm{o}} / \mathrm{A}_{\mathrm{s}}\left[\varepsilon_{\mathrm{l}}(\mathrm{t})-\varepsilon_{\mathrm{r}}(\mathrm{t})-\varepsilon_{\mathrm{t}}(\mathrm{t})\right]\right\}
$$

where $\mathrm{C}, \mathrm{E}$ and $\mathrm{A}_{\mathrm{O}}$ are the elastic wave velocity, elastic modulus and cross sectional areas of bars respectively. $L_{S}$ and $A_{S}$ are the gauge length and cross sectional area of the specimen. From equations (1) and (2), the relationship between mean stress $\sigma$ and strain $\varepsilon$ can be determined.

Fig. 26 shows the pattern of incident wave and reflective wave on S1000/EP[W] specimen at impact $\mathrm{V}=22 \mathrm{~m} / \mathrm{s}$. The patterns of the transmissive wave on $\mathrm{V}=22,24$ and 25 $\mathrm{m} / \mathrm{s}$ are shown in Fig. 27. In different test specimens, these wave patterns and forms were very similar within the range of velocities applied in this study. Fig. 28 shows the dynamic stress $(\sigma)$ vs time $(t)$ curves of S1000/EP[W] specimen at $\mathrm{V}=22,24$ and $25 \mathrm{~m} / \mathrm{s}$, while Fig. 29 shows the dynamic stress $(\sigma)$ and strain $(\varepsilon)$ relationship of S1000/EP[W] specimen at $\mathrm{V}=22 \mathrm{~m} / \mathrm{s}$.. When specimens did not rupture, the tendencies of the stress $(\sigma)-$ strain $(\varepsilon)$ curves were similar (Fig. 30). Each curve appears to be composed of linear segments of successively increasing slope, with maximum slope coinciding with maximum stress. This feature in dynamic tests is different from that of static tests. When $V$ reached $29.3 \mathrm{~m} / \mathrm{s}$, large specimen deformation occurred before failure. The slope of the curve decreases at this final stage

Table 7 summarizes the experimental results of high strain rate impact studies. It is clear that $\sigma_{\max }$ and $\varepsilon_{\max }$ and $\dot{\varepsilon}$ increase with increasing $\mathrm{V}$. Dynamic compression strengths obtained in this study is much greater than those from quasi-static tests. The shock strength 
was $739 \mathrm{MPa}$, and was several times higher than that of static strength. Thus ability of this material to withstand ballistic impact stress is superior.

Table 7 Dynamic Compression Properties of S1000/EP[W] Composites

\begin{tabular}{ccccc} 
Specimen Group & $\begin{array}{c}\text { Velocity } \\
\text { V(m/s) }\end{array}$ & $\begin{array}{c}\text { Stress max } \\
\sigma(\mathrm{MPa})\end{array}$ & $\begin{array}{c}\text { Strain max } \\
\varepsilon(\%)\end{array}$ & $\begin{array}{c}\text { Strain Rate } \\
\varepsilon\left(10^{3} \mathrm{~s}^{-1}\right)\end{array}$ \\
\hline 1 & 12.4 & 262 & 0.36 & 1.31 \\
2 & 16.1 & 353 & 0.50 & 1.44 \\
3 & 22.0 & 570 & 0.51 & 1.53 \\
4 & 25.1 & 624 & 0.62 & 1.68 \\
5 & 29.3 & 739 & 0.74 & 2.04
\end{tabular}

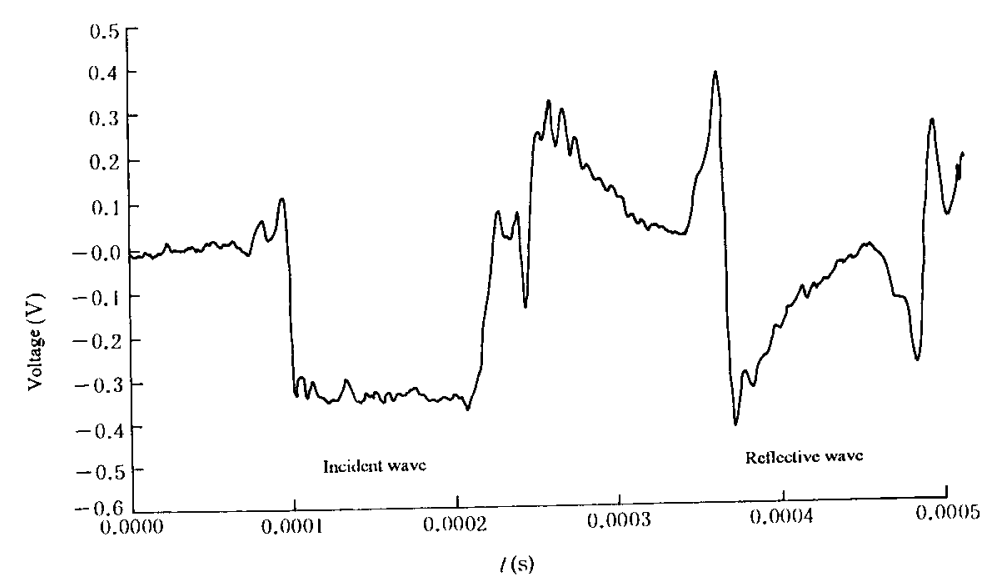

Fig. 26 The pattern of incident wave and reflective wave at high strain rate for S1000/EP $[\mathrm{W}](\mathrm{V}=22 \mathrm{~m} / \mathrm{s})$

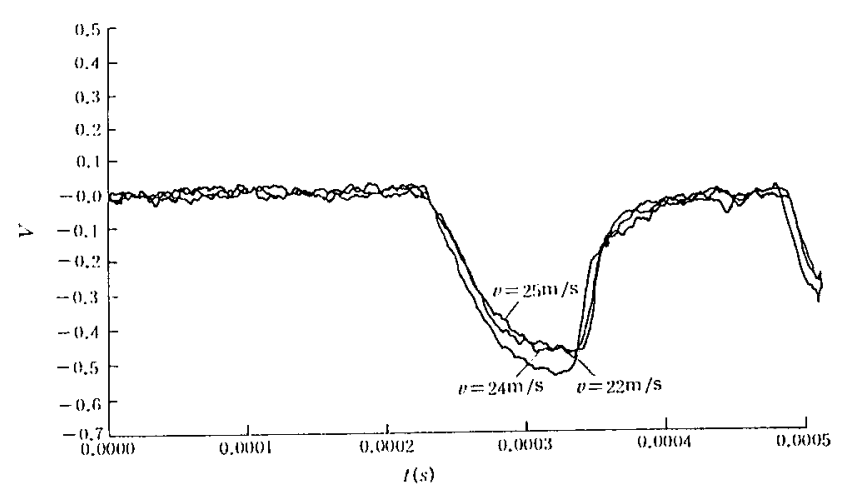

Fig. 27 Patterns of transmissive wave upon high strain rate impact for S1000/EP[W] specimen at $V=22 \mathrm{~m} / \mathrm{s}, 24 \mathrm{~m} / \mathrm{s}$ and $25 \mathrm{~m} / \mathrm{s}$ 


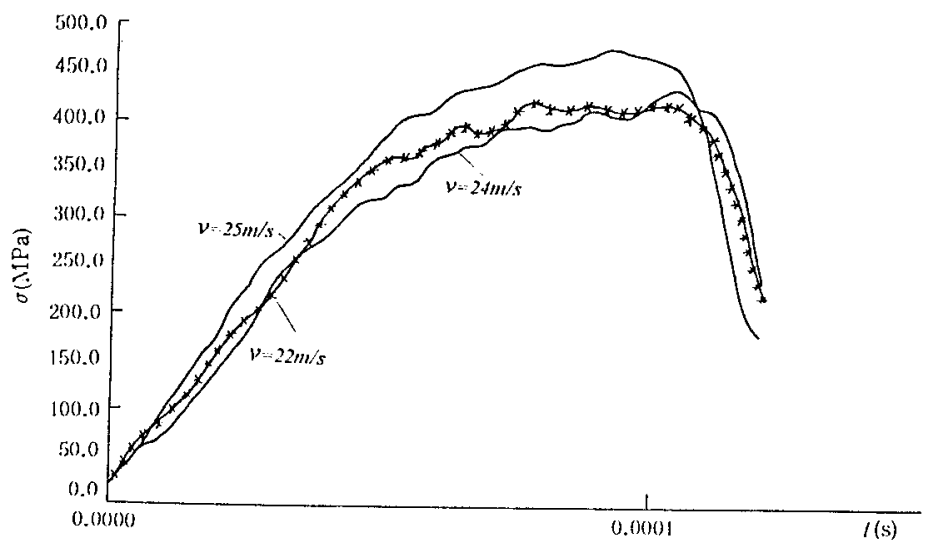

Fig.28 High strain rate compression impact $\sigma$-t curves for $S 1000 / E P[W]$ specimens

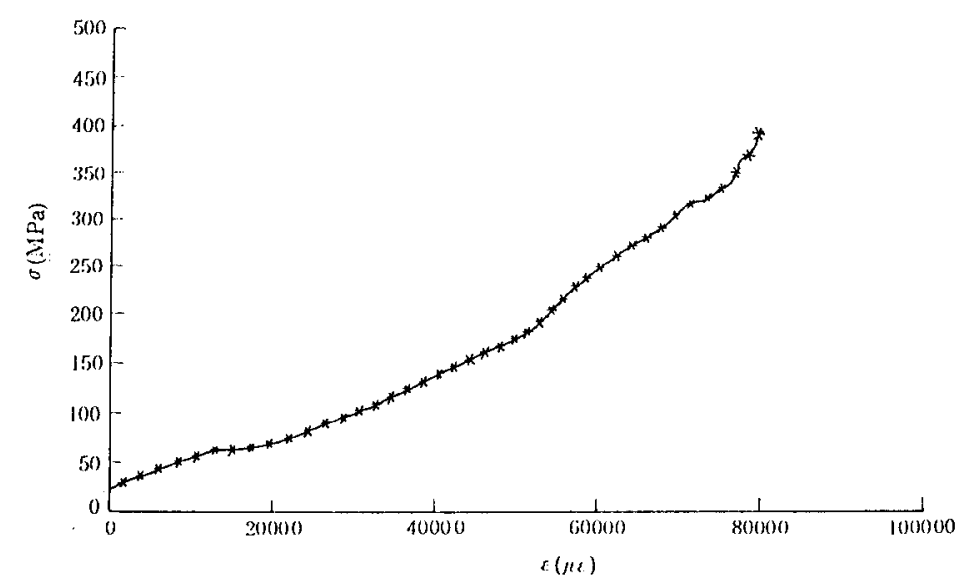

Fig.29 High strain rate compression impact $\sigma-\varepsilon$ curve for $S 1000 / E P[W]$ specimen $(V=22 \mathrm{~m} / \mathrm{s})$

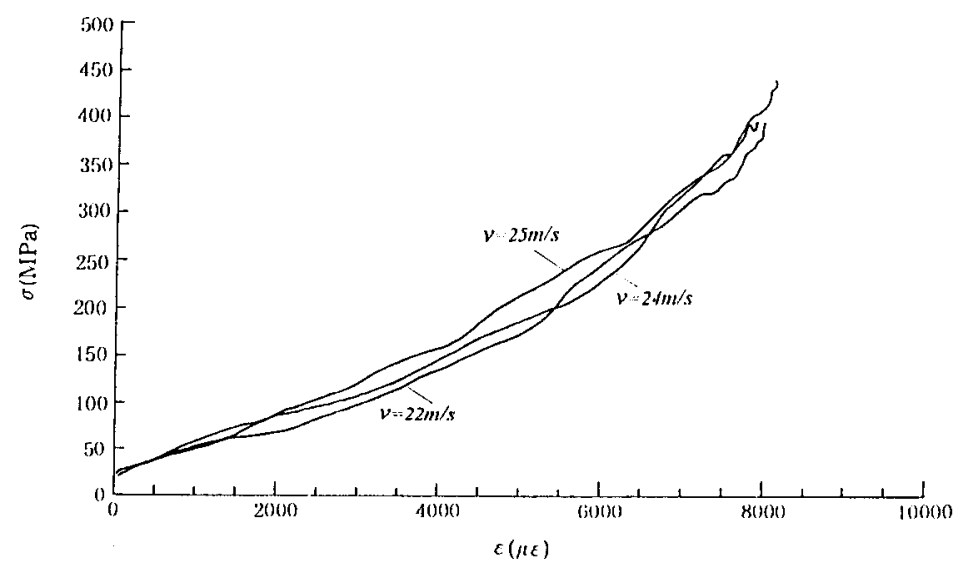

Fig.30 High strain rate compression impact $\sigma-\varepsilon$ curves for S1000/EP[W] specimens 


\subsection{Microscopic Failure Modes of S1000/EP[W] Composites After High Strain Rate Compression Impact}

Interlaminar spall was found to be a major failure mode of high strain rate impact on UHMPEF woven fabric composites. Under microscopic observation, it was found that various failure features resulted from different impact velocities. Fig. 31 to 34 are the SEM micrographs taken from specimens along the thickness direction at $\mathrm{V}=12.4,16.1,22.0$ and $25.1 \mathrm{~m} / \mathrm{s}$ respectively. At $\mathrm{V}=12.4 \mathrm{~m} / \mathrm{s}\left(\dot{\varepsilon}=1.31 \times 10^{3} \mathrm{~s}^{-1}\right)$, specimen thickness was shown to decrease by compression impact, but damages were not noted upon visual examination. Under SEM however (Fig. 31), cracks were seen along the woven fabric checks. At a higher $\mathrm{V}$ of $16.1 \mathrm{~m} / \mathrm{s}\left(\dot{\varepsilon}=1.44 \times 10^{3} \mathrm{~s}^{-1}\right)$ interlaminar spalls appeared in resin rich zones (Fig 32) and crushing of epoxy resin during impact become visible. At $\mathrm{V}=22 \mathrm{~m} / \mathrm{s}\left(\dot{\varepsilon}=1.53 \times 10^{3} \mathrm{~s}^{-1}\right)$ cavities and woven fabric checks were seen in addition to interlaminar spalls (Fig. 33). When $\mathrm{V}$ reached $25.1 \mathrm{~m} / \mathrm{s}\left(\dot{\varepsilon}=1.68 \times 10^{3} \mathrm{~s}^{-1}\right)$, specimen delamination and spalls became very serious, the fabric checks separated and extrusion of the UHMPE fibers were seen (Fig. 34). Complete failure occurred at $\mathrm{V}=29.3 \mathrm{~m} / \mathrm{s}\left(\dot{\varepsilon}=2.04 \times 10^{3} \mathrm{~s}^{-1}\right)$. Almost all the layers and fabric checks separated, and much interface debonding occurred (Fig. 35a). Ductile breakage was evident in the UHMPE fibers (Fig 35b). It is thus clear that at high strain rate impact, the degree of damage is much greater than those seen in static tests.

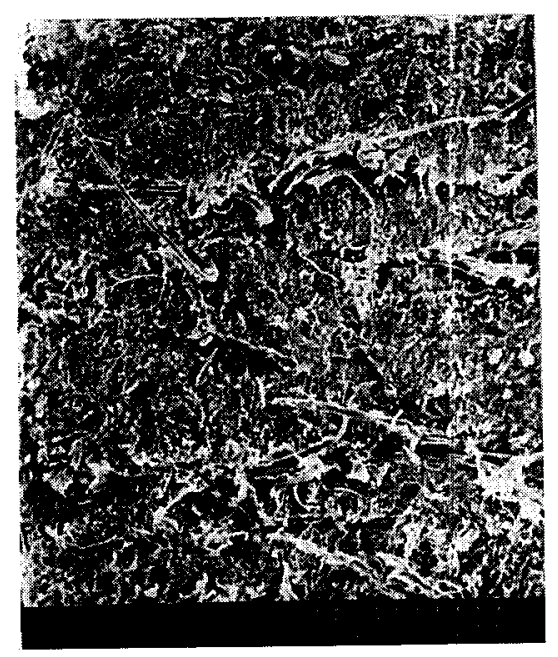

Fig. 31 Cracks occurred along the boundary of woven fabric checks in S1000/EP[W] specimen after high strain rate impact $(\dot{\varepsilon}=$ $1.31 \times 10^{3} \mathrm{~s}^{-1}$ )

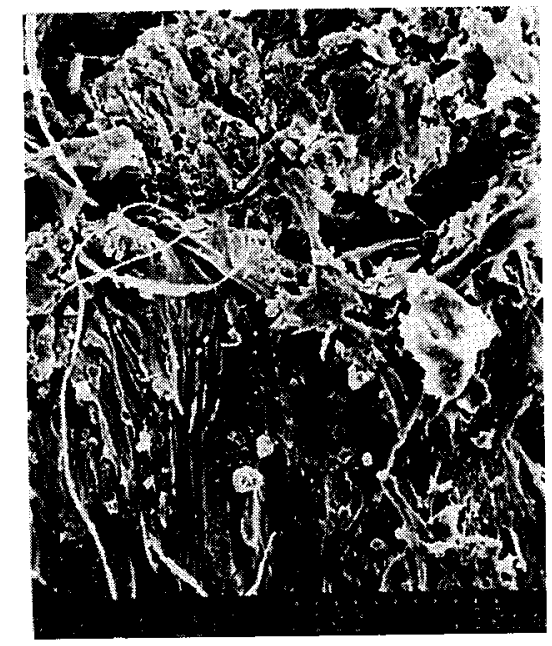

Fig.32 Interlaminar spall in resin rich zone and epoxy crash in S1000/EP[W] specimen after high strain impact $\left(\dot{\varepsilon}=1.44 \times 10^{3} \mathrm{~s}^{-1}\right)$ 


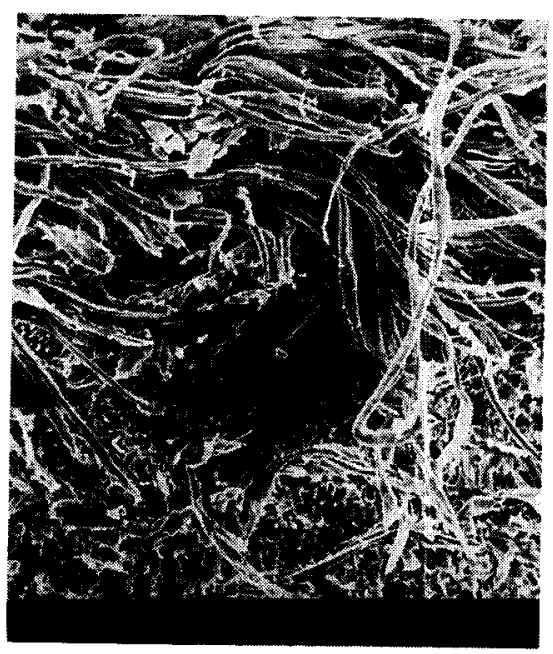

Fig.33 Interlaminar spallation and woven fabric checks loosed in S1000/EP[W]specimen after high strain rate compression impact $(\mathrm{V}=22 \mathrm{~m} / \mathrm{s})$

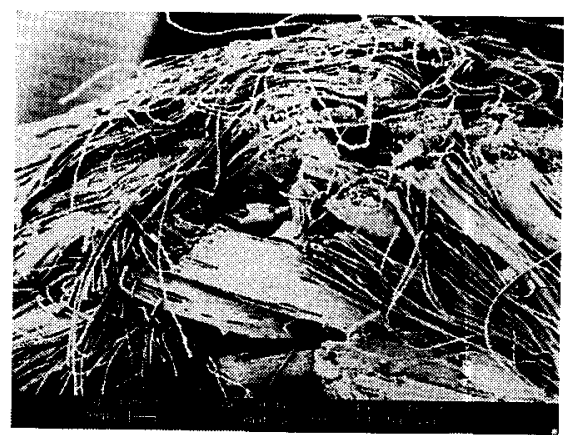

Fig. 35a Complete failure(fabric checks and interface debonding) in S1000/EP [W] specimen after high strain rate compression impact $(\mathrm{V}=29 \mathrm{~m} / \mathrm{s})$

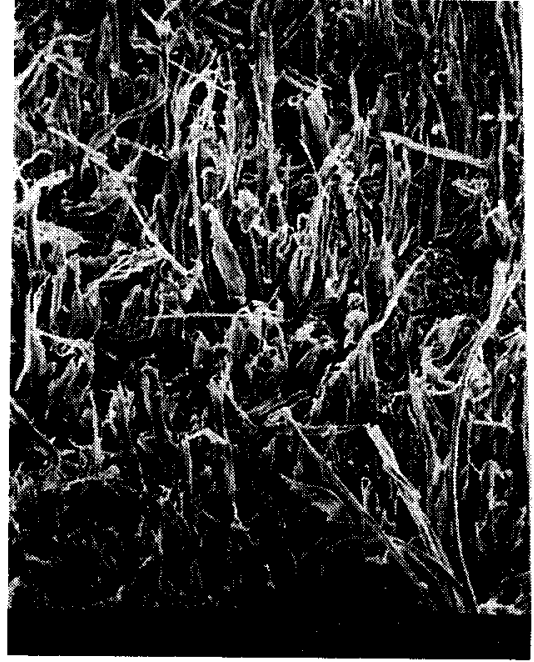

Fig.34 Woven fabric checks separated and fibers extruded in S1000/EP[W] specimen after high strain rate compession impact $(\mathrm{V}=25 \mathrm{~m} / \mathrm{s})$

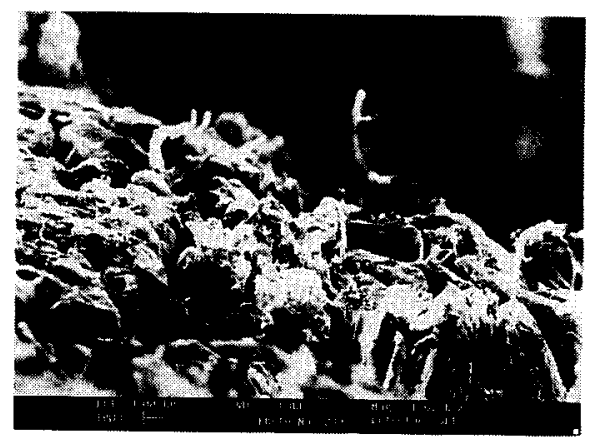

Fig. 35b Ductile breakage of S1000 fibers in woven specimen after high strain rate compression impact $(\mathrm{V}=29 \mathrm{~m} / \mathrm{s})$

\section{CONCLUSIONS}

Ultrahigh modulus polyethylene fiber composites have excellent impact resistance and against ballistic impact ability. This study shows that their impact properties are influenced by strain rate, stacking sequence, matrix type and fiber hybrid ratio.

The high ductility of UHMPEF fibers implies the sustenance of high strain at break, and together with a high tensile strength, results in superior impact resistance. This kind of fiber deform, but do not break easily under impact loading, and have good damage tolerance. During various damage processes such as deformation, delamination, spalling and fiber 
During various damage processes such as deformation, delamination, spalling and fiber breakage, UHMPE fibers absorb vast amounts of energy, both when the fiber is the sole reinforcement, or when hybridize with carbon fiber in hybrid composites. Under low velocity impact, deformation and delamination are the significant damage mechanisms, while spall and fiber breakage are the main failure mechanisms during high strain rate impact. Energy absorption from damage propagation energy is also significant. The specific impact resistance of UHMPE fiber composites are far superior to all other composite materials

In general, stress-strain curves obtained under high strain rates are more linear than those obtained under quasi-static and low energy impact tests. Impact strengths increase with rising strain rates. In a Charpy flat impact test at $\dot{\varepsilon}=5 \mathrm{~s}^{-1}$, the dynamic flexural stress of HHMPE fiber [0] composites are $20 \%$ higher than under static tests where $\dot{\varepsilon}=6 \times 10^{-4} \mathrm{~s}^{-1}$. When $\dot{\varepsilon}$ is in the range of $30-50 \mathrm{~s}^{-1}$, as typical of drop weight flat bending, flexural stress of S1000 fiber [W] composites increase to double their corresponding values in static tests. At the high strain rate $\dot{\varepsilon}=2.04 \times 10^{-3} \mathrm{~s}^{-1}$, the dynamic compression strength of S1000/EP [W] composites are several times those obtained under static tests. UHMPEF composites is family of materials that is sensitive to strain rate. This sensitivity varies according to the features of the composites, and increases for ductile composites. In contrast, for brittle composites tends to reduce strain rate sensitivity. For example, the tensile stressstrain curves of carbon fiber composites are similar in a range of $\dot{\varepsilon}$ from $8 \times 10^{-4} \mathrm{~s}^{-1}$ to $53 \mathrm{~S}^{-1}$. Their dynamic stress is slightly higher at $\dot{\varepsilon}=53 \mathrm{~s}^{-1}$. In the case of glass fiber composites, $\dot{\varepsilon}$ ranges from $8 \times 10^{-4} \mathrm{~s}^{-1}$ to $190 \mathrm{~s}^{-1}$ and their tensile stress is greater by $60 \%$. The former shows non-sensitivity to strain rate, and the latter shows sensitivity.

Because of the integration within the woven fabric structure, impact properties are higher than those of laminates. Chemical similarity between UHMPE fiber and the LDPE matrix improved interface adhesion, which contributed to a higher impact resistance in UHMPEF/ LDPE[W] composites than their epoxy counterparts.

By hybridizing with UHMPE fiber, the impact properties of carbon fiber composites have been improved significantly. In general, the improvement is correlated with the amount of UHMPE fiber in the composites. In particular, for Type 3 (UHMPEF-CF(1:1)/EP[0]) composites which had the largest number of layers in different fibers, much more energy was absorbed during impact, with delamination occurring at more UHMPEF-CF interfaces. In the hybrid composites, both kinds of fibers preserved their original features and failure modes upon impact loading. In conclusion, positive effects have been demonstrated in hybrid composites.

\section{ACKNOWLEDGEMENTS}

This work was supported by the Croucher Foundation of Hong Kong and Institute of Mechanics, Chinese Academy of Sciences. Allied-Signal Inc. supplied Spectra fiber and some composites. I am grateful to Miss $\mathrm{Y}$. Li for carrying out some of the measurements reported in this study. Valuable comments by Professor C.L.Choy of Hong Kong Polytechnic University are gratefuly acknowledged. 


\section{REFERENCES}

1. B.A.Byres, NASA Contract Report 159293, 1980

2. D.F.Adams and J.L.Perry, Testing and Evaluation(JTEVA), 1977, Vol 5,pp.114123.

3. J.N.Kirk, M.Munro and P.W.R.Beaumont, Mater. Sci. 1978, Vol.13, pp.21972204.

4. G.Marom, E.Drukker, A.Weinberg and J.Banbaji, Comp. 1986, Vol.17, No.2, pp. 150-153.

5. R.C.Wincklhofer and R.E.Rothwell, Oceans (New York), 1986, pp.278-283

6. N.H.Ladizesky and M.K.M.Pang, Comp. Sci. \& Tech. 1992, Vol.44, pp.127-136.

7. R.S.Porter, Eng. \& Polymer Sci. 1994, Vol.34, pp.266-268.

8. A.A.J.M.Peijs, R.W.Venderbosch and P.J.Lemstre, Comp. 1990, Vol.21, No.6, pp. 522-530.

9. N.H.Ladizesky and I.M.Ward, Comp. Sci. \& Tech. 1986, Vol.26, pp.199-224.

10. C.L.Choy, X.J.Xian and Z.Zhang, in Proceeding of Inter. Conference on Composites Materials and Structures, Beijing, 1992, pp.216-221.

11. X.J.Xian and C.L.Choy, in Proceeding of the Ninth Inter. Conference on Comp. Mater.(TCCM/9) M.Antonio, ed., Woodhead Publishing Ld., Madrid, 1993, pp.137-

144.

12. X.J.Xian, Y.M.Poon and C.L.Choy, Thermalplastic Comp. 1997, No.1, pp.151-162.

13. Y.Li, M.L.Guo, C.L.Choy, X.J.Xian and Z.G.Zhang, 1997, Acta Mater. Comp. Sinica, Vol. 14, No.3, pp.54-60.

14. Y.Li, C.L.Choy, M.L.Gue, X.J.Xian and Z.G.Zhang, Acta Mater. Comp. Sinca, 1997, Vol.14, No.2, pp.23-29.

15. X.Y.Xian, C.L.Choy, Y. Li, M.L.Guo and Z.G.Zhang, Comp. Sci. \& Tech. 1997, Submitted for Publication.

16. C.L.Choy, X.J.Xian and Q.S.Zhao, Proceedings of the Inter. Symposium on Polymer Alloys and Comp.(ISPAC), C.L.Choy and F.G.Shin, ed., Hong Kong, 1992, pp.304306.

17. P.W.R.Beaumont, P.G.Riewald and C.Zweben, in ASTM STP 568, American Society for Testing and Materials, 1875,pp.134-158.

18. X.J.Xian and C.L.Choy, Reinforced Plastics and Comp. Dec.1994,pp.1135-1141.

19. Products Brochure, Allied-Signal Inc

20. H.Kolsky, in Proc. Royal Soc. B. 1949, 62, pp. 676.

21. J.Harding and L.W.Welsh, Mater. Sci.1983, Vol.18, 1810-1826.

22. J.Rodiguez, I.S.Chocron, M.A.Martinez and V.Sanchez-Galvez, Comp. 1996, Vol. 27B, pp. 147-155.

23. Z. Duan, Advances in Mechanics, 1980, Vol.10, pp 1-9. 
Impact Response and Dynamic Failure of Composites and Laminate Materials

10.4028/www.scientific.net/KEM.141-143

Impact Response and Failure Mechanisms of Ultrahigh Modulus Polyethylene Fiber Composites and Polyethylene Fiber-Carbon Fiber Hybrid Composites

10.4028/www.scientific.net/KEM.141-143.187 